\title{
Dipole Moment and Anticancer Activity of Beta Lactams
}

\author{
APARNA DAS AND B. K. BANIK*
}

Department of Mathematics and Natural Sciences, College of Sciences and Human Studies, Prince Mohammad Bin Fahd University, Al Khobar 31952, Kingdom of Saudi Arabia

\section{Das et al.: Dipole Moment of Anticancer Beta Lactams}

This study investigates the correlation between in vitro anticancer activity and dipole moments of beta lactams by calculating the dipole moment with five different semiempirical methods (Austin model 1/Recife model 1/Parametric model number 3/Parametric model number 6/ Modified neglect of differential overlap). Dipole moment value is analyzed to identify a correlation of experimental anticancer activity of beta lactams. To the best of our knowledge, this is the first report on relationship between dipole moment and anticancer activities of beta lactams. Six beta lactam compounds are considered for this study. It is observed that the active compounds have a significantly higher dipole moment value (ranging from 5.12 to 4.3 ) compared to inactive compounds (ranging from 3.8 to 2.29). These data indicate that dipole moment might be a useful parameter for the estimation of the biological activity of beta lactams. This study also aims to determine the most prominent descriptor for cytotoxic activity of beta lactams to aid the development of more active anticancer agents.

Key words: Beta lactams, anticancer activity, dipole moment, Austin model 1, Recife model 1, parametric model number 3, parametric model number 6, modified neglect of differential overlap

Beta $(\beta)$ lactams are biologically active compounds. For example, these compounds have a wide range of medicinal activities, such as antibacterial ${ }^{[1]}$, antifunga ${ }^{[2]}$, anti-inflammatory ${ }^{[3]}$, cholesterol absorption inhibitors $^{[4-7]}$ anti-hepatitis ${ }^{[8]}$, antihyperglycemic ${ }^{[9]}$ and analgesic properties ${ }^{[10]}$. $\beta$-Lactams have received attention as a consequence of its anticancer ${ }^{[11-18]}$. Cancer is a deadly disease and its activity in human cell is extremely rapid. Most of the currently available anticancer drugs are cytotoxic to normal as well as to neoplastic cells. Therefore, there is highest need for new anticancer agents with a high degree of potency against cancerous cells, low toxicity in normal cells and unique targets of action. A slow success rate of chemotherapeutic agents has led to increased interest in the development of $\beta$-lactams. Over the past decade, synthesis ${ }^{[19-21]}$ and the anticancer activities of $\beta$-lactams derivatives have been widely studied by our group through a series of independent study ${ }^{[1-18]}$. During the course of this study, we realize an understanding and quantifying either intramolecular or intermolecular electronic interactions of $\beta$-lactams are required for further development. Towards this goal, in this study we have identified ground state dipole moment to correlate

*Address for correspondence

E-mail: bimalbanik10@gmail.com

September-October 2021 the anticancer activity of $\beta$-lactams. This study also helps to understand the influence of different substituted groups in the lactam rings. To our knowledge, this is the first study on revealing the correlation between dipole moment calculation and anticancer activities of $\beta$-lactams. Thus, this work is potentially significant and timely. Six different $\beta$-lactams used for dipole moment calculation were shown in fig. 1 . $\beta$-lactam 1 has a phenyl group linked to $\mathrm{N}_{1}$ position of the $\beta$-lactam ring, oxygen at the $\mathrm{C}_{2}$ position, an acetoxy group at the $\mathrm{C}_{3}$ position of the ring and a phenyl group at the $\mathrm{C}_{4}$ position as shown in 1(a) (fig. 1). To investigate the influence of the substituted groups, other compounds 2, 3, 4, 5 and 6 are also explored. For example, 2 has naphthalene group at the $\mathrm{N}_{1}$ position of the ring, 3 has anthracene group at the $\mathrm{N}_{1}$ position, 4 has phenanthrene group at the $\mathrm{N}_{1}$ position of the ring and 5 has chrysene group at the $N_{1}$ position of the ring. In 6 , we have interchanged the groups This is an open access article distributed under the terms of the Creative
Commons Attribution-NonCommercial-ShareAlike 3.0 License, which
allows others to remix, tweak, and build upon the work non-commercially,
as long as the author is credited and the new creations are licensed under
the identical terms

Accepted 02 September 2021

Revised 08 April 2021

Received 25 April 2020 Indian J Pharm Sci 2021;83(5):1071-1074 


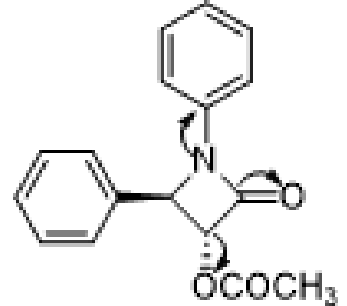

l(a)<smiles>CC(=O)OC1C(=O)[C@H](c2ccccc2)N(c2c3ccccc3cc3ccccc23)C1=O</smiles>

3(a)

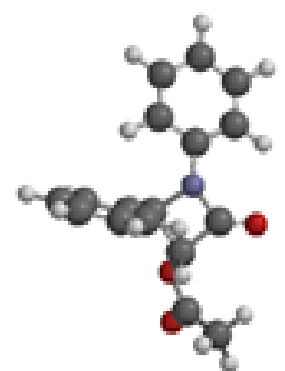

1(b)

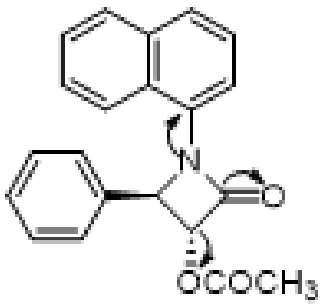

2(a)

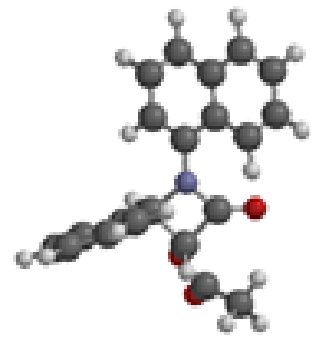

2(b)

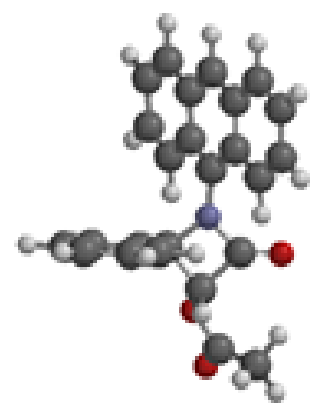

3(b)

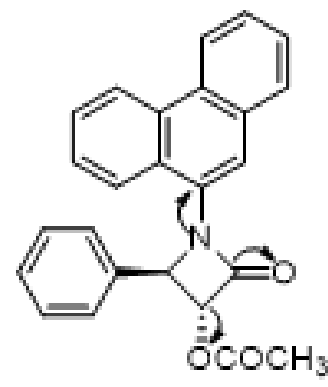

4(a)

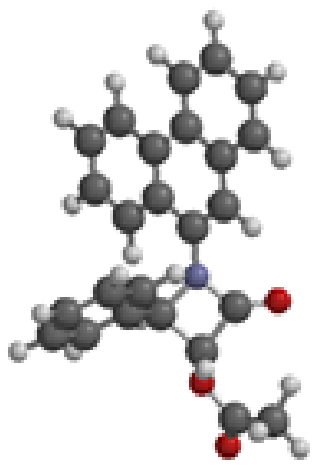

4(b)

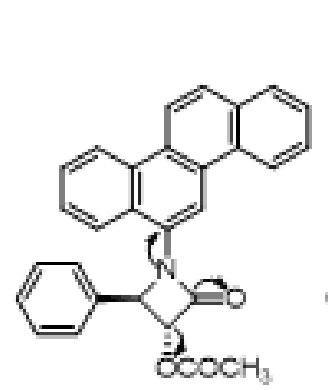

5 (a)

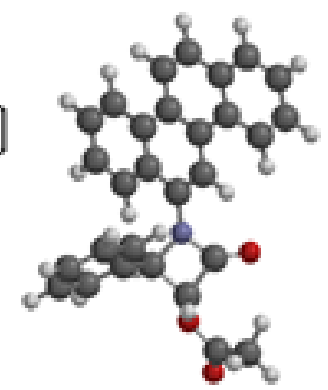

5(b)
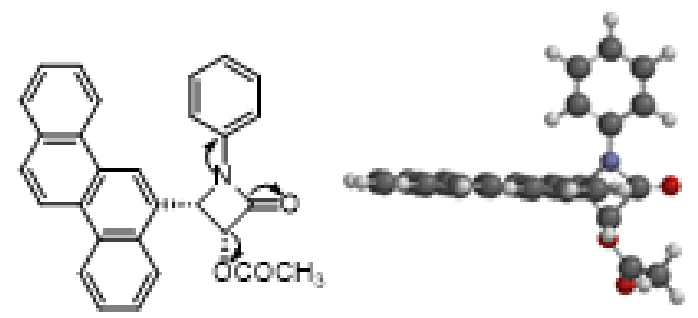

6(a) 6(b)

Fig. 1: $\beta$-lactam geometry used for dipole moment calculation

at $\mathrm{N}_{1}$ and $\mathrm{C}_{4}$ position, lactam 6 is a cis stereoisomer. Arrows are used to indicate movement of electrons in each structure. Dipole moment for the compounds was obtained using the Spartan 18 software package. The most successful ones and most frequently used methods are Modified Neglect of Differential Overlap $(\mathrm{MNDO})^{[22]}$, Austin Model 1 (AM1) ${ }^{[23]}$ and Parametric Model number $3(\mathrm{PM} 3)^{[24]}$. All are based on the Neglect of Differential Diatomic Overlap (NDDO) integral approximation. New versions of the NDDO methods have recently been developed by reparametrized the existing methods, leading to the Recife Model 1 (RM1) ${ }^{[25]}$ and Parametric Model number 6 (PM6) ${ }^{[26]}$ methods. In this study, we have used all these five methods for calculating dipole moment. All the measurements are performed with equilibrium geometry at ground state by changing AM1, RM1, PM3, PM6 and MNDO Hamiltonians. All the structures were drawn in two dimensional (2D) and then converted into their three dimensional (3D) forms using the same software followed by their energy minimization procedure. These result in most stereochemically stable structure of 
each compound, 1(b), 2(b), 3(b), 4(b), 5(b) and 6(b) in fig. 1. Anticancer activities of these $\beta$-lactams are shown in Table 1. Tests were done against nine human cancer cell lines. MDA-231 and MCF-7 are human breast cancer cells; BRO is human melanoma cells; OVCAR and SKOV are human ovarian cancer cells; HT-29 is human colon cancer cells; PC-3 is human prostate cancer cells; HL-60 and K-562 are human blood cancer cells. The details of synthesis and anticancer activity are discussed before ${ }^{[12]}$. The data from cisplatin, the anti-cancer chemotherapy drug, is included as a reference. It revealed that 1, 2, 3 and 6 are inactive against any of these cell lines and showed maximum activity at concentrations above $20 \mu \mathrm{M} / \mathrm{ml}$ (a level not considered to have a significant effect). $\beta$-lactams 4 and 5 demonstrated significant anticancer activity. Both of these compounds showed almost identical activity with cisplatin against some cell lines (MCF-7) and showed more activity than cisplatin against some cell lines (HT-29). The calculated ground state dipole moment $(\mu)$ value in Debye (D) for the mentioned six $\beta$-lactam compounds is shown in Table 2. It is observed that $\beta$-lactam 4 (phenanthrene group at the $\mathrm{N}_{1}$ position of the ring) and 5 (chrysene group at the $\mathrm{N}_{1}$ position of the ring) showed highest value of dipole moment, ranging from 5.12 to $4.3 \mathrm{D}$. Compared to other selected calculations methods, MNDO calculation giving lowest value for dipole moment (except in 2 and 6). From the dipole moment calculation and anticancer activity data, we believe that there is a direct relation with dipole

TABLE 1: In vitro CYTOTOXICITY OF $\beta$-LACTAMS ON HUMAN CANCER CELL LINES $(\mu \mathrm{M})$

\begin{tabular}{lcccc}
\hline Cell lines & Cisplatin & $\mathbf{4}$ & $\mathbf{5}$ & $\mathbf{1 , 2 , 3 , 6}$ \\
\hline OVCAR & 3.99 & 18.0 & 4.17 & $>20$ \\
BRO & 7.66 & 10.48 & 10.84 & $>20$ \\
MDA-231 & 12.33 & 12.49 & 11.98 & $>20$ \\
MCF-7 & 10.05 & 10.09 & 9.81 & $>20$ \\
SKOV & 5.99 & 18.0 & 6.88 & $>20$ \\
PC-3 & 4.66 & 9.3 & 16.32 & $>20$ \\
HL-60 & 1.66 & 5.21 & 3.64 & $>20$ \\
K-562 & 2.33 & 4.0 & 4.33 & $>20$ \\
HT-29 & 16.99 & 10.49 & 5.66 & $>20$ \\
\hline
\end{tabular}

TABLE 2: CALCULATED DIPOLE MOMENT VALUES IN DEBYE (D)

\begin{tabular}{lccccc}
\hline B-lactams & AM1 & RM1 & PM3 & PM6 & MND0 \\
\hline 1 & 3.07 & 2.66 & 3 & 2.72 & 2.29 \\
2 & 2.94 & 2.80 & 3.33 & 3.15 & 3.5 \\
3 & 2.91 & 2.66 & 3.15 & 3.01 & 2.42 \\
4 & 5.15 & 5.10 & 4.89 & 4.55 & 4.30 \\
5 & 5.12 & 5.07 & 4.89 & 4.51 & 4.34 \\
6 & 3.53 & 3.07 & 2.27 & 3.8 & 2.69 \\
\hline
\end{tabular}

moment and anticancer activity of $\beta$-lactams. Only 4 and 5 demonstrated anticancer activity and their dipole moment was high (above $4.3 \mathrm{D}$ ) compared to other $\beta$-lactam compounds. Dipole moment is strongly dependent on the substitution at the $\mathrm{N}_{1}$ site, which suggested that the position of the substituted group influenced the anticancer activity. Dipole moment is directly affected by the arrangement of aromatic rings at the $\mathrm{N}_{1}$ site. Linear arrangements of aromatic rings (anthracene group, naphthalene group) make the compound less polar. Angular arrangements of aromatic rings (chrysene group, phenanthrene group) make the compound more polar by making large separation of charges in $\beta$-lactams. Anticancer activity test also had identified that the minimal structural requirement of the aromatic moiety for cytotoxicity is at least three aromatic rings in an angular configuration like in chrysene and phenanthrene group.

This explanation is not valid for compounds 5 and 6 . The compounds 5 and 6 are isomeric, but with different stereochemistry at the ring junction. They showed different dipole moment and anticancer activity. The inactive compound 6 has much less dipole moment compared to 5. It is again confirmed that at least three aromatic rings in an angular configuration must be present in $\mathrm{N}_{1}$ position of the ring. The substituted $\beta$-lactam ring plays an important role for electron density variation. Angular arrangements of aromatic rings in chrysene and phenanthrene group at the nitrogen of the ring act as strong electron-withdrawing groups that result in strong polar compounds. We have demonstrated that there is a relation between the dipole moment and anticancer activity of $\beta$-lactam compounds. Six different compounds were analyzed with five different dipole moment calculations. Dipole moment is high, above $4.3 \mathrm{D}$, for active compounds. This study also revealed that the substitutional group at the $\mathrm{N}_{1}$ in the $\beta$-lactam ring plays an important role for its anticancer activity. These results may open a way to design and synthesis more active anticancer $\beta$-lactam. This study, however, does not specify that high dipole moment controls anticancer activity of $\beta$-lactam compounds. Rather, we have identified a correlation between the dipole moment and anticancer activity of $\beta$-lactam compounds. This study is unique since such explorations with $\beta$-lactams and their anticancer activity have never been performed. Further studies in this area with other $\beta$-lactams are necessary to define the role of dipole moment and we are pursuing our research in this direction. 


\section{Acknowledgements:}

Aparna Das and Bimal Krishna Banik are grateful to Deanship of research and Prince Mohammad Bin Fahd University for support. Bimal Krishna Banik is also grateful to United States (US) National Institutes of Health (NIH), US National Cancer Institute (NCI) and Kleberg Foundation of Texas for financial support.

\section{Conflicts of interest:}

The authors confirm that this result has no conflict of interest.

\section{REFERENCES}

1. Sperka T, Pitlik J, Bagossi P, Tozser J. Beta-lactam compounds as apparently uncompetitive inhibitors of HIV-1 protease. Bioorg Med Chem Lett 2005;15(12):3086-90.

2. O'Driscoll M, Greenhalgh K, Young A, Turos E, Dickey S, Lim DV. Studies on the antifungal properties of $\mathrm{N}$-thiolated $\beta$-lactams. Bioorg Med Chem 2008;16(16):7832-7.

3. Srivastava SK, Srivastava SL, Srivastava SD. Synthesis of new 2-chloro-phenothiazinothiadiazol-2-oxoaze tidines: Antimicrobial and antiinflammatory agents. Indian J Chem 2000;39B:464-7.

4. Clader JW, Burnett DA, Caplen MA, Domalski MS, Dugar $\mathrm{S}$, Vaccaro $\mathrm{W}$, et al. 2-Azetidinone cholesterol absorption inhibitors: Structure activity relationships on the heterocyclic nucleus. J Med Chem 1996;39(19):3684-93.

5. Clader JW. The discovery of ezetimibe: a view from outside the receptor. J Med Chem 2004;47(1):1-9.

6. Burnett DA, Caplen MA, Davis Jr HR, Burrier RE, Clader JW. 2-Azetidinones as inhibitors of cholesterol absorption. J Med Chem 1994;37(12):1733-6.

7. Burnett DA. $\beta$-Lactam cholesterol absorption inhibitors. Curr Med Chem 2004;11(14):1873-87.

8. Lall MS, Ramtohul YK, James MN, Vederas JC. Serine and threonine $\beta$-lactones: a new class of hepatitis A virus $3 \mathrm{C}$ cysteine proteinase inhibitors. J Org Chem 2002;67(5):153647.

9. Goel RK, Mahajan MP, Kulkarni SK. Evaluation of antihyperglycemic activity of some novel monocyclic beta lactams. J Pharm Pharm Sci 2004;7(1):80-3.

10. Saturnino C, Fusco B, Saturnino P, De Martino G, Rocco F, Lancelot JC. Evaluation of analgesic and anti-inflammatory activity of novel $\beta$-lactam monocyclic compounds. Biol Pharm
Bull 2000;23(5):654-6.

11. Banik BK, Becker FF, Banik I. Synthesis of anticancer $\beta$-lactams: Mechanism of action. Bioorg Med Chem 2004;12(10):2523-8.

12. Banik BK, Banik I, Becker FF. Stereocontrolled synthesis of anticancer $\beta$-lactams via the Staudinger reaction. Bioorg Med Chem 2005;13(11):3611-22.

13. Banik BK, Becker FF. Selective anticancer activity of $\beta$-lactams derived from polyaromatic compound. Mol Med Rep 2010;3(2):315-6.

14. Banik BK, Banik I, Becker FF. Asymmetric synthesis of anticancer $\beta$-lactams via Staudinger reaction: Utilization of chiral ketene from carbohydrate. Eur $\mathrm{J}$ Med Chem 2010;45(2):846-8.

15. Banik BK. Heterocyclic Scaffolds I, Top. Topics in Heterocyclic Chemistry. New York: Springer; 2010. p. 1-379.

16. Banik BK. $\beta$-Lactams: Synthesis and biological evaluation. Topics in Heterocyclic Chemistry. New York: Springer; 2012.

17. Banik I, Banik BK. Microwave-induced chemical manipulation of $\beta$-lactam. New York: Springer; 2012. p. 781-1007.

18. Banik BK. Beta-lactams: Novel synthetic pathways and applications. New York: Springer; 2017.

19. Bandyopadhyay D, Cruz J, Banik BK. Novel synthesis of 3-pyrrole substituted $\beta$-lactams via microwave-induced bismuth nitrate-catalyzed reaction. Tetrahedron 2012;68(52):10686-95.

20. Bandyopadhyay D, Rhodes E, Banik BK. A Green, chemoselective and practical approach toward N-(2azetidinonyl)-2,5-disubstituted pyrroles. RSC Adv 2013;3:16756-64.

21. Banik I, Becker FF, Banik BK. Stereoselective synthesis of $\beta$-lactams with polyaromatic imines: Entry to new and novel anticancer agents. J Med Chem 2003;46(1):12-5.

22. Dewar MJ, Thiel W. Ground states of molecules. 38. The MNDO method. Approximations and parameters. J Am Chem Soc 1977;99(15):4899-907.

23. Dewar MJ, Zoebisch EG, Healy EF, Stewart JJ. Development and use of quantum mechanical molecular models. 76. AM1: A new general purpose quantum mechanical molecular model. J Am Chem Soc 1985;107:3902-9.

24. Stewart JJ. Optimization of parameters for semiempirical methods II. Applications. J Comput Chem 1989;10(2):221-64.

25. Rocha GB, Freire RO, Simas AM, Stewart JJ. RM1: A reparameterization of $\mathrm{AM} 1$ for $\mathrm{H}, \mathrm{C}, \mathrm{N}, \mathrm{O}, \mathrm{P}, \mathrm{S}, \mathrm{F}, \mathrm{Cl}, \mathrm{Br}$, and I. J Comput Chem 2006;27(10):1101-11.

26. Stewart JJ. Optimization of parameters for semiempirical methods V: Modification of NDDO approximations and application to 70 elements. J Mol Model 2007;13(12):1173213. 